\title{
Remifentanil functions in the adaptive protection of cardiac function following ischemia
}

\author{
JIE HOU, HUISHAN WANG, XINMIN LI and YAN ZHU
}

\begin{abstract}
Department of Cardiac Surgery, The General Hospital of Shenyang Military Region, Shenyang, Liaoning 110016, P.R. China
\end{abstract}
Received January 26, 2015; Accepted October 8, 2015

DOI: 10.3892/etm.2017.4124

\begin{abstract}
The present study aimed to investigate the effects of remifentanil during adaptation followinsg myocardial ischemia, and its possible clinical applications. Remifentanil was used during the simulation of adaptation following ischemia, which was performed using a Langendorff heart perfusion system. A total of 75 rats were divided into five groups, and the coronary flow, cardiac output and the cardiac enzyme content in coronary effluent prior to ischemia and post-reperfusion were recorded. Electron microscopy was used to observe myocardial ultrastructure, and the volume of aortic and coronary effluent was also measured. The recovery of cardiac output upon reperfusion was significantly higher following remifentanil treatment $(91 \%)$, as compared with the ischemic control group $(78 \%$; $\mathrm{P}<0.05)$. The coronary flow of the experimental group following reperfusion decreased by $4 \mathrm{ml} / \mathrm{min}$ compared with the control group not exposed to ischemia, whilst the coronary flow of the ischemic control group was reduced by $20-24 \mathrm{ml} / \mathrm{min}$. Flameng scoring of the mitochondria demonstrated improved mitochondrial ultrastructure following remifentanil treatment (score, $1.25 \pm 0.31$ ), as compared the ischemic control group (score, $3.14 \pm 0.17$ ). Lactate dehydrogenase (LDH) levels in the remifentanil-treated group were significantly lower at 10 and 30 min post-reperfusion $(15.3 \pm 7.1$ and $10.2 \pm 6.8 \mathrm{U} / 1$, respectively), as compared with the control group (29.7 \pm 8.3 and $20.6 \pm 6.8 \mathrm{U} / 1$, respectively; $\mathrm{P}<0.05)$. The results of the present study suggested that the application of remifentanil following ischemia protected heart function via the opioid receptors by reducing myocardial enzyme release, and attenuating ischemia-induced changes to the myocardial cell and mitochondrial structure.
\end{abstract}

Correspondence to: Professor Huishan Wang, Department of Cardiac Surgery, The General Hospital of Shenyang Military Region, 83 Wenhua Road, Shenyang, Liaoning 110016, P.R. China E-mail: sqdoccn@126.com

Key words: myocardial protection, post-adaptation, remifentanil, opioid receptor agonist, Langendorff working model

\section{Introduction}

Ischemic-reperfusion injury often occurs during surgical procedures for heart disease, including bypass heart surgery and coronary revascularization, and affects treatment efficacy (1). The symptoms of ischemic-reperfusion injury include myocardial cell edema, changes in the ultrastructure of cells, microvascular damage, a persistent low ventricular systolic function, myocardial enzyme release and reperfusion arrhythmias (2). Murry et al (3) demonstrated that the myocardium develops increased resistance against permanent injury following repeated, transient episodes of ischemia and reperfusion; this is known as ischemic preconditioning (IPC). A previous study demonstrated that IPC was able to alleviate reperfusion injury, reduce the extent of myocardial necrosis, and prevent the occurrence of reperfusion arrhythmias (4). However, since it is difficult to accurately determine when ischemia may arise, the potential therapeutic application of IPC is greatly limited. Zhao et al (5) initially proposed the concept of ischemic postconditioning (IPO), which involves brief periods of ischemia during reperfusion $(6,7)$, in 2003. It is thought that IPO may reduce the extent of myocardial infarction and myocardial enzyme release, and the occurrence of reperfusion arrhythmias.

Opioids, including morphine, ohmefentanyl and enkephalin, have been used prior to and following coronary artery bypass surgery to treat acute myocardial ischemia, in order to treat patients with pain and post-operative analgesia (8). It has previously been demonstrated that the application of opioids during cardiac surgery imitates the process of IPO, thereby providing broad therapeutic potential (9).

In the present study, IPO was stimulated using the Langendorff isolated heart perfusion working model (10), in conjunction with use of the opioid receptor agonist remifentanil. In this model, the cardiac output and cardiac enzyme levels were measured, and the changes to myocardial cells and the mitochondria were observed. The present study aimed to investigate the effects of remifentanil during IPO, as well as its therapeutic potential in the treatment of ischemic-reperfusion injury.

\section{Materials and methods}

Animals and grouping. A total of 75 healthy, 6-week-old male rats with body weights of 200-300 $\mathrm{g}$ (China Medical University Experimental Animal Center, Beijing, China) were randomly 
divided into 5 groups (Fig. 1). In the control group ( $\mathrm{n}=15$ rats), the rat hearts were perfused continuously with blood using a Langendorff heart perfusion system (Beijing Zhishuduobao Biological Technology Co., Ltd., Beijing, China), with no additional treatment and without ischemia, for the same duration as the treatment of the other groups. In the ischemia-reperfusion group ( $\mathrm{n}=15$ rats), stable perfusion was implemented for $10 \mathrm{~min}$ and stopped for $30 \mathrm{~min}$ to cause global ischemia, then reperfusion was applied for $80 \mathrm{~min}$ with no additional treatment. In the treatment groups $(n=15$ rats each), stable perfusion was again implemented for $10 \mathrm{~min}$ and stopped for $30 \mathrm{~min}$ to cause global ischemia. The rats were then continuously administered a fixed concentration of drug for $1 \mathrm{~min}$ at a pressure of $50 \mathrm{mmHg}$; following this, reperfusion with blood was implemented, as aforementioned, for the remaining $79 \mathrm{~min}$. The agonist group received $100 \mu \mathrm{g} / \mathrm{l}$ remifentanil (Yichang Humanwell Pharmaceutical Co., Ltd., Yichang, China), the naxolone (opioid antagonist) group were administered $300 \mu \mathrm{g} / 1$ naloxone (Hebei Aoxing Pharmaceutical Group Co., Ltd., Shijiazhuang, China) and the agonist plus antagonist group ( $\mathrm{n}=15$ rats) received $100 \mu \mathrm{g} / 1$ remifentanil and $300 \mu \mathrm{g} / \mathrm{l}$ naloxone simultaneously. The present study was performed in strict accordance with the recommendations in the Guide for the Care and Use of Laboratory Animals of the National Institutes of Health (Bethesda, MA, USA), and the animal use procedure was reviewed and approved by the Institutional Animal Care and Use Committee of the General Hospital of Shenyang Military Region (Shenyang, China).

Establishment of an isolated heart model. To anesthetize the rats, $4 \mathrm{ml} / \mathrm{kg} 10 \%$ chloral hydrate (Sigma-Aldrich, St. Louis, MO, USA) was intraperitoneally injected $5 \mathrm{~min}$ prior to subsequent treatment. Heparinization was then performed by intraperitoneally injecting $500 \mathrm{U} / \mathrm{kg}$ heparin (Sigma-Aldrich) to prevent blood clotting. The rats were fixed in a supine position and operated upon under sterile conditions. An incision was made transversely along the anterior abdominal wall and along the costal margin. The abdomen was incised between the head end and the xiphoid process of the sternum, and across the diaphragm. Cuts were then made longitudinally across the chest, along the center line of the clavicle, on each side of the body. The anterior mediastinal tissues were separated, the anterior chest wall was opened over the head and the heart was exposed. The heart was rapidly and carefully removed by incising the aorta and other vasculature, starting from 4-5 mm into the initial portion of the aorta. The heart was immediately placed in the $4^{\circ} \mathrm{C}$, pre-treated Krebs-Henseleit (K-H) solution (Sigma-Aldrich), saturated with $95 \% \mathrm{O}_{2}$ and $5 \% \mathrm{CO}_{2}$ at a rate of $1.5 \mathrm{l} / \mathrm{min}$ and rinsed, and then the blood was gently extruded.

The aorta was opened using ophthalmic forceps for cannulation and the Langendorff heart perfusion system was placed at the perfusing entrance. This system consisted of a double hollow glass tube; an outer section was supplied with heated water, and upper and lower entrances were connected to a thermostatic water pump pipe. The inner layer was filled with K-H solution, and the inner tube had two entry ports. The upper entrance was used for the addition of K-H solution, in order to maintain a constant perfusion pressure, and the lower port was connected to the aorta. The aortic cannula was connected to the heart via 3 tubes. The aortic root was below the surface of the

\begin{tabular}{|c|c|c|c|}
\hline $\begin{array}{l}\text { Control } \\
\text { group }\end{array}$ & \multicolumn{3}{|c|}{ Continuous perfusion for $120 \mathrm{~min}$} \\
\hline $\begin{array}{c}\text { Ischemia } \\
\text { group }\end{array}$ & $\begin{array}{c}\text { Stable } \\
\text { for } 10 \mathrm{~min}\end{array}$ & $\begin{array}{l}\text { Ischemia for } \\
30 \mathrm{~min}\end{array}$ & Reperfusion for $80 \mathrm{~min}$ \\
\hline$\underset{\text { group }}{\text { Remifentanil }}$ & $\begin{array}{c}\text { Stable } \\
\text { for } 10 \mathrm{~min}\end{array}$ & $\begin{array}{c}\text { Ischemia for } \\
30 \mathrm{~min}\end{array}$ & Reperfusion for $79 \mathrm{~min}$ \\
\hline $\begin{array}{l}\text { Naloxone } \\
\text { group }\end{array}$ & $\begin{array}{c}\text { Stable } \\
\text { for } 10 \mathrm{~min}\end{array}$ & $\begin{array}{l}\text { Ischemia for } \\
30 \mathrm{~min}\end{array}$ & Reperfusion for $79 \mathrm{~min}$ \\
\hline $\begin{array}{l}\text { Remifentanil } \\
+ \text { Naloxone } \\
\text { group }\end{array}$ & \begin{tabular}{|c|} 
Stable \\
for $10 \mathrm{~min}$
\end{tabular} & $\begin{array}{c}\text { Ischemia for } \\
30 \mathrm{~min}\end{array}$ & Reperfusion for $79 \mathrm{~min}$ \\
\hline
\end{tabular}

Figure 1. Allocation of experimental groups and perfusion time. Gray region indicates that remifentanil $(100 \mu \mathrm{g} / \mathrm{l})$, naloxone $(300 \mu \mathrm{g} / 1)$ or a co-treatment of the two were continuously administered for $1 \mathrm{~min}$ at a pressure of $50 \mathrm{mmHg}$ prior to reperfusion.

water during the whole experiment and the insertion position of the perfusion fluid output port catheter into the aortic root was higher than the aortic valve level. The apparatus was fixed in place with a fourth silk ligature, following which constant cardiac perfusion was performed. The perfusion pressure was maintained at $80 \mathrm{~cm} \mathrm{H}_{2} \mathrm{O}$, and the beating heart was observed at random intervals. Bilateral pulmonary vein ligation was performed by inserting the horn cone catheter (with a diameter of $3 \mathrm{~mm}$ ) into the left atrial appendage; this was connected to a constant pressure reservoir bottle, and its height was adjusted to cause a left atrial load of $13 \mathrm{~cm} \mathrm{H}_{2} \mathrm{O}$. The isolated heart was subjected to Langendorff perfusion with an aortic load of $80 \mathrm{~cm} \mathrm{H}_{2} \mathrm{O}$. Perfusion was performed as aforementioned.

Hemodynamic measurement. The volumes of aortic fluid and coronary flow were measured by collecting the aortic and coronary effluent, respectively, and the cardiac output was calculated as a control. Following reperfusion, these metrics were recorded following 10 and $30 \mathrm{~min}$ of activity by the left ventricle. These were compared with corresponding values prior to cardiac arrest to attain the percentage change resulting from post-ischemic reperfusion [change $(\%)=$ (value of reperfusion / value prior to cardioplegia) x 100].

Enzyme determination. The coronary effluent at $5 \mathrm{~min}$ prior to cardiac arrest and the left ventricular output at 10 and $30 \mathrm{~min}$ after reperfusion were collected. An RT-200C Plus Automated Chemistry Analyzer (Shenzhen Leidu Life Sciences Co., Ltd., Shenzhen, China) was used to measure lactate dehydrogenase (LDH) and levels of 2 phosphocreatine kinase (CK-MB) variants.

Electron microscopic observation. A total of 3 specimens from each group were randomly selected for examination by electron microscopy. Preparation involved multiple steps, as follows: Apical slices of $\sim 1 \mathrm{~mm}$ of myocardial tissue from each group were sectioned, placed in $2.5 \%$ glutaraldehyde (Sigma-Aldrich) and rinsed with phosphate-buffered saline (PBS) three times (with a duration of $30 \mathrm{~min}$ for each rinse). Samples were fixed with $1 \%$ osmium tetroxide (Sigma-Aldrich) for $2 \mathrm{~h}$ and rinsed with PBS three times. Sections were then subjected to alcohol and acetone gradient dehydration, involving treatment with $50 \%$ ethanol for $30 \mathrm{~min}, 70 \%$ ethanol for $30 \mathrm{~min}, 80 \%$ acetone for 
Table I. Myocardial enzyme changes prior to ischemia ( $\mathrm{n}=15$ rats per group; mean \pm standard deviation).

\begin{tabular}{lccr}
\hline $\begin{array}{l}\text { Index/ } \\
\text { group }\end{array}$ & $\begin{array}{c}\text { Prior to } \\
\text { ischemia }\end{array}$ & $\begin{array}{c}\text { Reperfusion } \\
\text { for } 10 \mathrm{~min}\end{array}$ & $\begin{array}{r}\text { Reperfusion } \\
\text { for } 30 \mathrm{~min}\end{array}$ \\
\hline LDH, U/1 & & & \\
Control & $9.3 \pm 1.2$ & $9.2 \pm 1.1$ & $9.0 \pm 1.5$ \\
Ischemia & $9.1 \pm 2.1$ & $29.7 \pm 8.3$ & $20.6 \pm 8.0$ \\
Remifentanil & $9.2 \pm 1.8$ & $15.3 \pm 7.1^{\mathrm{a}}$ & $13.2 \pm 6.8^{\mathrm{a}}$ \\
Naloxone & $8.8 \pm 1.5$ & $25.6 \pm 8.1$ & $19.8 \pm 7.5$ \\
Remifentanil & $8.9 \pm 1.7$ & $26.4 \pm 6.9$ & $21.4 \pm 7.1$ \\
+ naloxone & & & \\
CK-MB, U/1 & & & \\
Control & $1.8 \pm 0.5$ & $1.7 \pm 1.0$ & $1.7 \pm 0.7$ \\
Ischemia & $2.1 \pm 0.7$ & $5.8 \pm 1.5$ & $3.4 \pm 1.2$ \\
Remifentanil & $2.2 \pm 0.8$ & $6.1 \pm 2.0$ & $4.0 \pm 2.0$ \\
Naloxone & $2.0 \pm 0.4$ & $6.0 \pm 1.4$ & $3.6 \pm 2.2$ \\
Remifentanil & $1.9 \pm 0.3$ & $6.7 \pm 2.1$ & $3.7 \pm 1.3$ \\
+ naloxone & & & \\
\hline
\end{tabular}

${ }^{\text {ap }}<0.05$ vs. the ischemic control group. $\mathrm{LDH}$, lactate dehydrogenase; CK-MB, phosphocreatine kinase.

$30 \mathrm{~min}$ (Sigma-Aldrich) and 90\% acetone for $30 \mathrm{~min}$, followed by three washes (of $30 \mathrm{~min}$ each) with $100 \%$ acetone. These sections were embedded and permeated in epoxy resin (Wuxi Guangming Chemical Co., Ltd., Wuxi, China) and ultra-thin 70-nm slices were prepared using an LKB microtome (LKB Corp., Stockholm, Sweden). The slices were stained with uranyl acetate (Sigma-Aldrich) for $15 \mathrm{~min}$ and with lead citrate (Yingkou Tianyuan Chemical Research Institute Co., Ltd., Yingkou, China) for $20 \mathrm{~min}$. Flameng scoring of the mitochondria was performed under a 1200 EX Transmission Electron Microscope (JEOL, Ltd., Tokyo, Japan), according to a previous study (11). A total of 5 fields of view were randomly selected from each slice, and each field included 20 mitochondria. The mean \pm standard deviation of the mitochondrial scores for each field were calculated and scored as follows: Normal mitochondrial structure and intact particle, 0 points; normal mitochondrial structure but missing particles, 1 point; mitochondrial swelling and transparent matrix, 2 points; steep rupture and transparent and concentrated matrix, 3 points; and rupture, and incomplete inner and outer mitochondrial membranes, 4 points.

Statistical analysis. Statistical analysis was performed using the SPSS 13.0 software package (SPSS Inc., Chicago, IL, USA). Data are expressed as the mean \pm standard deviation and comparisons among groups were performed using an analysis of variance. $\mathrm{P}<0.05$ was considered to indicate a statistically significant difference.

\section{Results}

General data. In total, 75 rats were used in the present study. The body weight of each rat was between 229 and 246 g, with no significant difference between the groups. The measured
Table II. Cardiac output volume changes following ischemia ( $\mathrm{n}=15$ rats per group; mean \pm standard deviation).

\begin{tabular}{lccc}
\hline & & \multicolumn{2}{c}{$\begin{array}{c}\text { Cardiac output volume } \\
\text { recovery rate, } \%\end{array}$} \\
\cline { 3 - 4 } Groups & $\begin{array}{c}\text { Output prior } \\
\text { to ischemia, } \\
\text { ml/min }\end{array}$ & $\begin{array}{c}\text { 10-min } \\
\text { reperfusion }\end{array}$ & $\begin{array}{c}\text { 30-min } \\
\text { reperfusion }\end{array}$ \\
\hline Control & $30.3 \pm 2.5$ & $96.1 \pm 7.5$ & $95.2 \pm 7.1$ \\
Ischemia & $29.4 \pm 4.5$ & $78.4 \pm 7.9$ & $67.2 \pm 8.2$ \\
Remifentanil & $28.9 \pm 5.3$ & $91.1 \pm 8.1^{\text {a }}$ & $78.1 \pm 7.5^{\text {a }}$ \\
Naloxone & $31.7 \pm 2.3$ & $77.2 \pm 7.1$ & $68.1 \pm 7.3$ \\
Remifentanil & $28.1 \pm 3.3$ & $79.1 \pm 8.3$ & $69.6 \pm 9.1$ \\
+ naloxone & & & \\
\hline aP<0.05 vs. the ischemic control group. & \\
\hline
\end{tabular}

heart rate prior to and following perfusion fluctuated within a range of 300 beats/min, but no significant difference between the groups was observed.

Enzymatic changes. LDH and CK-MB levels prior to ischemia were not significantly different between the rats from each group. However, LDH levels in the coronary effluent at $5 \mathrm{~min}$ and $10 \mathrm{~min}$ of reperfusion following ischemia were significantly lower in the remifentanil treatment group than the other ischemia-reperfusion groups $(\mathrm{P}<0.05)$; the differences between the other ischemia-reperfusion groups were not significant $(\mathrm{P}>0.05)$ (Table I; Fig. 2A and B). CK-MB values measured prior to ischemia and after reperfusion for $5 \mathrm{~min}$ and $10 \mathrm{~min}$ were also not identified as significantly different.

Heart function. The cardiac output of the non-ischemic control group during the entire reperfusion did not significantly alter. When examining the cardiac output between 10 and 30 min of reperfusion following ischemia, the remifentanil-treated group demonstrated a significantly higher cardiac output recovery rate than the other ischemia-reperfusion groups $(\mathrm{P}<0.05)$, but no significant difference was identified between the other groups ( $>>0.05$; Table II; Fig. 2C). Coronary blood flow of the remifentanil-treated group following ischemia-reperfusion decreased by $\sim 4 \mathrm{ml} / \mathrm{min}$ when compared with the control group not exposed to ischemia, but the reduction in coronary blood flow reached up to $20-24 \mathrm{ml} / \mathrm{min}$ less than the corresponding non-ischemic values in the other groups $(\mathrm{P}<0.05$; Tables II and III; Fig. 2D).

Myocardial ultrastructure. The myocardial fibers and mitochondria were observed using electron microscopy (Table IV). In the control group, muscle fibers were appropriately arranged, the organelles were clear, and the mitochondrial outer membrane and crests were intact (Fig. 3A). In the ischemic control group, muscle fibers were disordered, mitochondrial crests were reduced and the mitochondrial outer membranes were damaged (Fig. 3B). The remifentanil group tissues exhibited appropriately-arranged, mitochondria-rich muscle fibers, and the mitochondrial crest 
Table III. Effects of opioid receptor agonist on cardiac coronary flow, $\mathrm{ml}$ ( $\mathrm{n}=15$ rats per group; mean \pm standard deviation).

\begin{tabular}{lcccccc}
\hline Groups & $30-35 \mathrm{~min}$ & $35-40 \mathrm{~min}$ & $70-75 \mathrm{~min}$ & $75-80 \mathrm{~min}$ & $110-115 \mathrm{~min}$ & $115-120 \mathrm{~min}$ \\
\hline Control & $56.60 \pm 3.42$ & $56.07 \pm 3.33$ & $55.13 \pm 3.00$ & $54.47 \pm 2.42$ & $54.53 \pm 3.27$ & $54.13 \pm 3.54$ \\
Ischemia & $55.93 \pm 4.43$ & $54.73 \pm 3.15$ & $32.00 \pm 4.61$ & $31.87 \pm 3.87$ & $32.20 \pm 3.61$ & $31.27 \pm 4.91$ \\
Remifentanil & $56.73 \pm 4.86$ & $55.87 \pm 4.26$ & $54.93 \pm 4.64^{\mathrm{a}}$ & $53.87 \pm 5.17^{\mathrm{a}}$ & $53.53 \pm 5.14^{\mathrm{a}}$ & $52.47 \pm 5.67^{\mathrm{a}}$ \\
Naloxone & $57.73 \pm 4.27$ & $57.67 \pm 3.98$ & $32.73 \pm 2.99$ & $32.87 \pm 3.85$ & $32.40 \pm 4.00$ & $32.20 \pm 3.90$ \\
Remifentanil & $56.93 \pm 3.77$ & $56.53 \pm 3.46$ & $33.20 \pm 2.54$ & $33.27 \pm 1.71$ & $33.93 \pm 2.58$ & $33.67 \pm 2.85$
\end{tabular}

+ naloxone

${ }^{\mathrm{a}} \mathrm{P}<0.05$ vs. the ischemia, naloxone and remifentanil + naloxone groups.

A

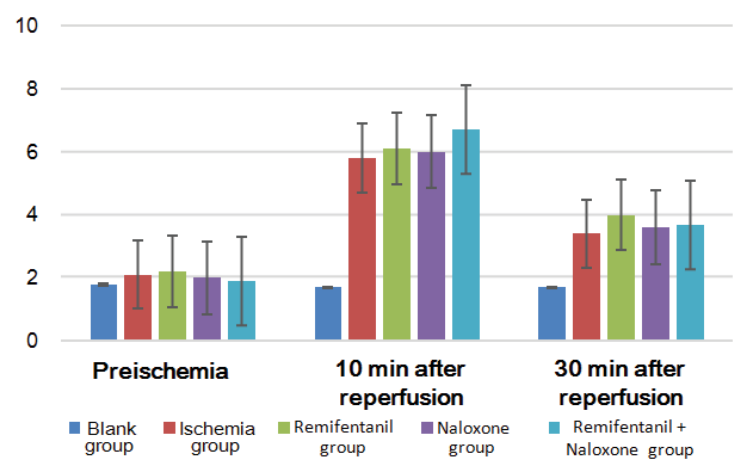

C Effect of opioid receptor agonist on coronary flow

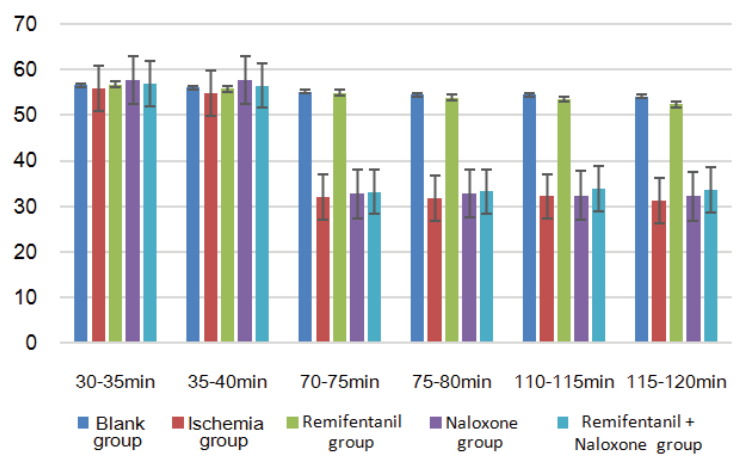

B

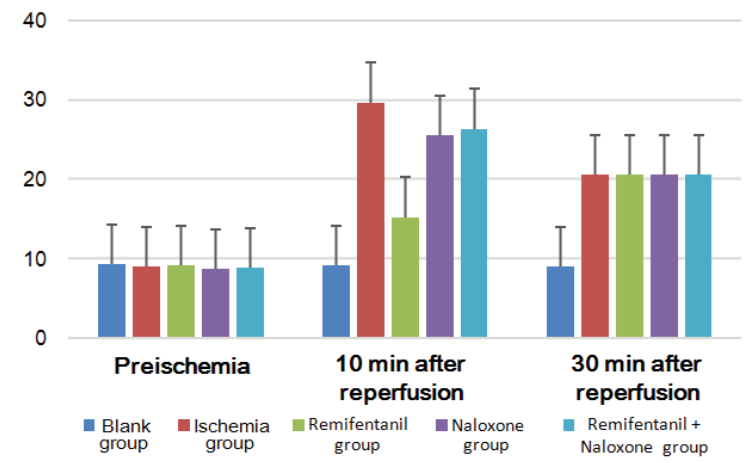

D

Changes of cardiac output post-ischemic

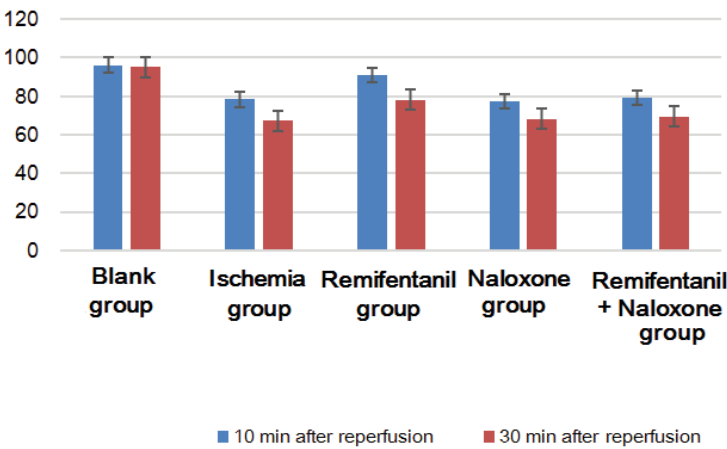

Figure 2. Effects of enzymatic changes and heart function prior to and following ischemia on (A) LDH, (B) CK-MB, (C) cardiac coronary blood flow and (D) cardiac output. LDH, lactate dehydrogenase; CK-MB, phosphocreatine kinase.

and outer membrane had maintained their integrity (Fig. 3C). Treatment with naloxone led to disorganized muscle fibers, reduced mitochondrial crests and vacuolar degeneration (Fig. 3D). In the remifentanil and naloxone co-treatment group, myocardial lines were blurred, and the mitochondrial crest and outer membrane were damaged (Fig. 3E).

\section{Discussion}

Zhao et al (5) first proposed IPO as a potent endogenous protective mechanism in 2003; the molecular details of this mechanism remain unclear, but are an area of active study in the field of cardiology (12). Sun et al (13) hypothesized that the reduction of oxygen free radicals during early reperfusion may be the main cause of post-reperfusion injury; this argument was supported and refuted by subsequent studies. Tsang et al (14) used the phosphoinositide 3-kinase (PI3K) inhibitor wortmannin to successfully attenuate the cardioprotective effect of ischemic post-adaptation, hypothesizing that PI3K-Akt-endothelial nitric oxide synthase, not PI3K, is the primary mediator of post-ischemic adaptation. Ischemic adaptation may, therefore, be mediated by multiple signal transduction pathways (15). Previous studies of adaptation mechanisms indicated that opioid receptor agonists have cardioprotective effects, and receptor activation and intracellular information transmission are the predominant focus of these (16-18).

In the present study, the aortic effluent volume was measured using isolated heart working models. The cardiac output in the opioid receptor agonist-treated group recovered to $\sim 91 \%$ of the cardiac output measurement of the group not subjected to 
A

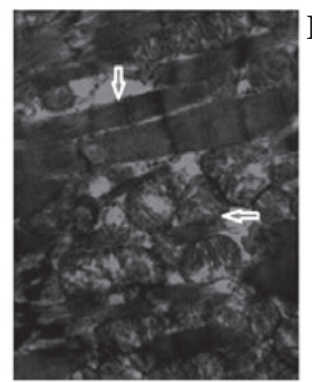

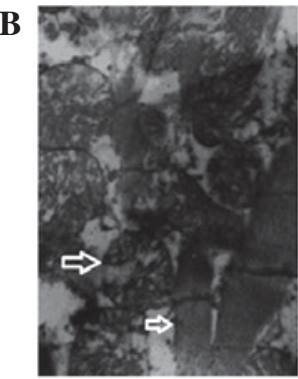
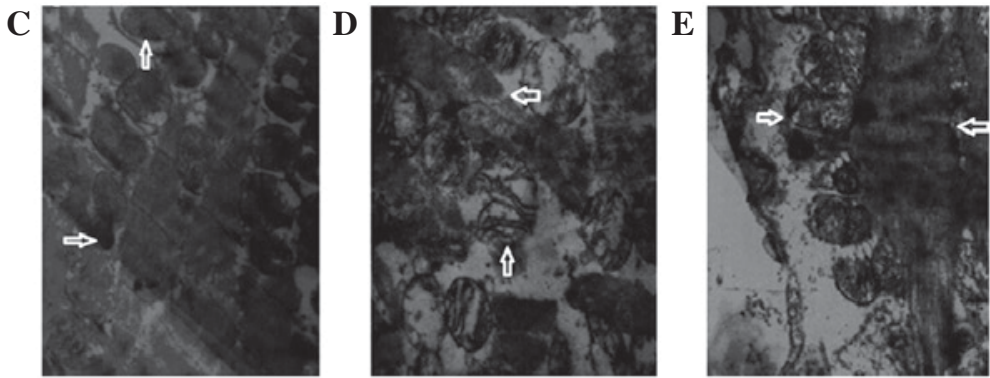

Figure 3. Changes to myocardial ultrastructure, observed using electron microscopy (magnification, 1,300,000x). (A) Non-ischemic control group; muscle fibers were correctly arranged, the sensitive sectors were clear, and the outer mitochondrial membrane and crests were complete. (B) Ischemic control group; muscle fibers were disordered, the mitochondrial crests were reduced and the outer mitochondrial membranes were damaged. (C) Remifentanil-treated group; muscle fibers were correctly arranged and rich in mitochondria, and the mitochondrial crests and outer membranes had retained their integrity. (D) Naloxone-treated group; muscle fibers were disorganized, the mitochondrial crests were reduced and vacuoles were degenerated. (E) Remifentanil and naloxone co-treated group; cardiac lines were blurred, and the mitochondrial crests and outer membranes were defective. The white arrows indicate the mitochondria and mitochondrial cristae of the myocardial cells.

ischemia, which was far higher than that of the ischemic control group (78\%). Remifentanil was able to significantly increase the volume of aortic outflow and cardiac output when compared with the ischemic control group. This myocardial protective effect disappeared upon treatment with opioid receptor antagonists, which resulted in a cardiac output recovery at $79 \%$ of that of the group not subjected to ischemia. These results indicate that the cardioprotective effects of post-conditioning may be accomplished, at least in part, by opioid receptors. The coronary blood flow following reperfusion in the remifentanil-treated group was less than that of the group not subjected to ischemia ( $\sim 4 \mathrm{ml} / \mathrm{min}$ ), but the equivalent data from the ischemic control group demonstrated a greater, $20-24 \mathrm{ml} / \mathrm{min}$ reduction. There were significant differences in coronary blood flow between the groups following ischemia-reperfusion, which may explain the cardioprotective effect of the opioid receptor agonist.

A previous study has indicated that opioid receptor agonists can protect diastolic and systolic function following ischemia-reperfusion (19). Kin et al (20) revealed that an opioid receptor agonist had no effect on myocardial diastolic and systolic function prior to ischemia, but that the left ventricular end-diastolic pressure (LVEDP) of the agonist group prior to ischemia increased more slowly and that cardiac spasmodic contraction occurred later than in the control group. In this study, the left ventricular pressure in the opioid receptor agonist group after $30 \mathrm{~min}$ reperfusion recovered to $85 \%$ of its value prior to ischemia, but in the control group, the left ventricular pressure only reached $45 \%$ of its pre-ischemia pressure. The LVEDP of the agonist group was significantly lower than that of the control group.

The present study simulated adaptation following myocardial ischemia, using an opioid receptor agonist remifentanil to demonstrate that this has a cardioprotective effect. Heart coronary blood flow and cardiac output were significantly different to the ischemic control group; due to the significant improvement in cardiac function in the agonist group and the attenuation of this effect upon treatment with an opioid receptor antagonist, it can be concluded that the cardioprotective effect was accomplished by opioid receptors. The remifentanil used in this experiment was a specific receptor agonist, whereas naloxone was a non-selective opioid receptor antagonist, suggesting that certain opioid receptor agonists can

Table IV. Effect of opioid receptor agonist on mitochondria in cardiac muscle cells (mean \pm standard deviation).

Group

Flameng score for mitochondria

Control

Ischemia

Remifentanil

Naloxone

Remifentanil + naloxone

${ }^{a} \mathrm{P}<0.05$ vs. the control group.

significantly reduce the impact of ischemia-reperfusion injury on cardiac function, in addition to improving heart function and increasing coronary blood flow and cardiac output. These roles were performed via opioid receptors, but the exact mechanism behind this effect remains unknown.

Mitochondria have an important function in the energy provision for cells, and can also regulate the osmotic pressure, calcium balance, $\mathrm{pH}$ value and intracellular signal transduction pathways of the cell (21). The present study noted the appearance of the mitochondrial ion channels and scored the protective effect of the opioid receptor agonist remifentanil upon the mitochondria. The mitochondrial score of the agonist-treated group was $1.25 \pm 0.31$, which was significantly lower than the score of $3.14 \pm 0.17$ observed in the ischemic control group. The LDH and CK-MB levels were determined in order to deduce the protective effect of the opioid receptor agonist upon the myocardial cells. The measured LDH level of the remifentanil-treated group following 10 and $30 \mathrm{~min}$ of reperfusion was $15.3 \pm 7.1$ and $10.2 \pm 6.8 \mathrm{U} / 1$, respectively, while the ischemic control group demonstrated significantly higher values of $29.7 \pm 8.3$ and $20.6 \pm 6.8 \mathrm{U} / 1$, respectively. It could thus be concluded that remifentanil had roles in protecting the myocardial mitochondria when administered during myocardial adaptation following ischemia, associated with enzyme release during this process. The corresponding values in the naxolone and naxolone + remifentanil groups were $25.6 \pm 8.1$ and $26.4 \pm 6.9 \mathrm{U} / 1$, supporting the hypothesis that this process is mediated by opioid receptors. 
Mitochondrial function is essential to a positive cardiac outcome following ischemia-reperfusion (22); if mitochondria are damaged during reperfusion, this can result in an insufficient adenosine triphosphate (ATP) supply, meaning that the ischemic myocardial damage cannot be repaired. If mitochondria are protected, however, myocardial cell function can gradually recover to avoid causing irreversible damage (23). It has previously been suggested that mitochondrial calcium overload is an important contributory factor to myocardial injury during ischemia-reperfusion (24). Free and stable $\mathrm{Ca}^{2+}$ regulation is necessary for ATP production in the mitochondria (25). A previous study has indicated that myocardial ischemia-reperfusion is accompanied by $\mathrm{Ca}^{2+}$ influx into the mitochondria and concomitant calcium orthophosphate deposition, following which mitochondrial oxidative phosphorylation and thus energy metabolism are disturbed, leading to a reduction in ATP production (26).

Calcium influx causes the mitochondrial permeability transition pore (MPTP) in the inner mitochondrial membrane to open, causing the destruction of the mitochondria and the hydrolysis of ATP $(27,28)$. MPTP opening, resulting from mitochondrial matrix calcium overload and often associated with oxidative stress, is also hypothesized to be causative of myocardial ischemia-reperfusion injury (29). A previous study indicated that, under low mitochondrial matrix ATP and high Pi conditions, opioid receptor agonists protect myocardial mitochondrial function in response to ischemia-reperfusion injury (30). This may be directly implemented by the mitochondria to prevent calcium uptake, or may be due to inhibition of myocardial MPTP opening by oxygen free radical scavengers $(29,31)$.

In the present study, electron microscopy and Flameng scoring demonstrated that the degree of mitochondrial swelling and the number of fragmented mitochondria in the experimental group was significantly decreased compared with that in the ischemic control group, and myocardial enzyme level measurements supported these conclusions. Remifentanil may thus have a cardioprotective role in myocardial cells, functioning by reducing the release of cardiac enzymes and protecting mitochondria in myocardial cells, as supported by the evidence for these roles in the current study; however, its specific mechanism of action remains to be studied.

The current study revealed that opioid receptor agonists had a significant role in improving heart function and protecting myocardial cells, increasing coronary blood flow and cardiac output, reducing myocardial enzyme release and protecting mitochondria. These effects were hypothesized to occur by the activation of these receptors in myocardial cells; this may present therapeutic potential, if administered during early cardiac reperfusion, in improving cardiac function and protecting the myocardium. For instance, remifentanil may be used for myocardial protection in early reperfusion during cardiac bypass surgery or in early revascularization in the treatment of coronary heart disease. However, the present study was performed in an animal model, meaning that these effects may not be replicated in humans; therefore, the recovery of cardiac function in patients following surgery and the improvement of post-operative outcome require further investigation.

\section{References}

1. Carden DL and Granger DN: Pathophysiology of ischaemia-reperfusion injury. J Pathol 190: 255-266, 2000.

2. Naito H, Furukawa Y, Chino D, Yamada C, Hashimoto K: Effects of zatebradine and propranolol on canine ischemia and reperfusion-induced arrhythmias. Eur J Pharmacol 388: 171-176, 2000.

3. Murry CE, Jennings RB and Reimer KA: Preconditioning with ischemia: A delay of lethal cell injury in ischemic myocardium. Circulation 74: 1124-1136, 1986.

4. Miura T, Miura T, Kawamura S, Goto M, Sakamoto J, Tsuchida A, Matsuzaki M and Shimamoto K: Effect of protein kinase C inhibitors on cardioprotection by ischemic preconditioning depends on the number of preconditioning episodes. Cardiovasc Res 37: 700-709, 1998.

5. Zhao ZQ, Corvera JS, Halkos ME, Kerendi F, Wang NP, Guyton RA and Vinten-Johansen J: Inhibition of myocardial injury by ischemic postconditioning during reperfusion: Comparison with ischemic preconditioning. Am J Physiol Heart Circ Physiol 285: H579-H588, 2003.

6. Jennings RB: Historical perspective on the pathology of myocardial ischemia/reperfusion injury. Circ Res 113: 428-438, 2013.

7. Hausenloy DJ: Cardioprotection techniques: Preconditioning, postconditioning and remote conditioning (basic science). Curr Pharm Des 19: 4544-4563, 2013.

8. Umegaki $\mathrm{H}$ and Tagami N: Anesthetic management of an ALS patient with remifentanil. Masui 57: 1139-1142, 2008 (In Japanese).

9. Zhang G, Sun Y, Wang Y, Bai J, Li T, Li X, Su S and Liu X: An improved postconditioning algorithm: Gradually increased reperfusion provides improved cardioprotection in rats. Mol Med Rep 8: 696-702, 2013.

10. Finegan BA, Gandhi $M$ and Clanachan AS: Phentolamine prevents the adverse effects of adenosine on glycolysis and mechanical function in isolated working rat hearts subjected to antecedent ischemia. J Mol Cell Cardiol 32: 1075-1086, 2000.

11. Flameng W, Borgers M, Daenen W and Stalpaert G: Ultrastrutural and cytochemical correlates of myocardial protection by cardiac hypothermia in man. J Thorac Cardiovasc Surg 79: 413-424, 1980.

12. Tong G, Aponte AM, Kohr MJ, Steenbergen C, Murphy E and Sun J: Postconditioning leads to an increase in protein S-nitrosylation. Am J Physiol Heart Circ Physiol 306: H825-H832, 2014.

13. Sun K, Liu ZS and Sun Q: Role of mitochondria in cell apoptosis during hepatic ischemia-reperfusion injury and protective effect of ischemic postconditioning. World J Gastroenterol 10: 1934-1938, 2004.

14. Tsang A, Hausenloy DJ, Mocanu MM and Yellon DM: Postconditioning: A form of 'modified reperfusion' protects the myocardium by activating the phosphatidylinositol 3-kinase-Akt pathway. Circ Res 95: 230-232, 2004.

15. Zhao Q, Shao L, Hu X, Wu G, Du J, Xia J and Qiu H: Lipoxin a4 preconditioning and postconditioning protect myocardial ischemia/reperfusion injury in rats. Mediators Inflamm 2013: 231351, 2013.

16. Vinten-Johansen J, Zhao ZQ, Zatta AJ, Kin H, Halkos ME and Kerendi F: Postconditioning - A new link in nature's armor against myocardial ischemia-reperfusion injury. Basic Res Cardiol 100: 295-310, 2005.

17. Zhao TC, Du J, Zhuang S, Liu P and Zhang LX: HDAC inhibition elicits myocardial protective effect through modulation of MKK3/Akt-1. PLoS One 8: e65474, 2013.

18. Takata K, Tomiyama Y, Tanaka K and Oshita S: Cardioprotective effects of hyperkalemia during simulated ischemia/reperfusion in neonatal rat cardiomyocytes - Preservation of $\mathrm{Na}^{+} / \mathrm{K}^{+}$-ATPase activity. J Med Invest 60: 66-76, 2013.

19. Babiker FA, Joseph S and Juggi J: The protective effects of 17beta-estradiol against ischemia-reperfusion injury and its effect on pacing postconditioning protection to the heart. J Physiol Biochem 70: 151-162, 2014.

20. Kin H, Zatta AJ and Jiang R: Activation of opioid receptors mediates the infarct postconditioning. J Mol Cell Cardiol 38: 827,2005

21. Yellon DM and Hausenloy DJ: Myocardial reperfusion injury. $\mathrm{N}$ Engl J Med 357: 1121-1135, 2007.

22. Widgerow AD: Ischemia-reperfusion injury: Influencing the microcirculatory and cellular environment. Ann Plast Surg 72: 253-260, 2014. 
23. Perrelli MG, Tullio F, Angotti C, Cerra MC, Angelone T, Tota B, Alloatti G,Penna C and Pagliaro P: Catestatin reduces myocardial ischaemia/reperfusion injury: Involvement of PI3K/Akt, PKCs, mitochondrial KATP channels and ROS signalling. Pflugers Arch 465: 1031-1040, 2013

24. Cui J, Li Z, Qian LB, Gao Q, Wang J, Xue M, Lou XE, Bruce IC, Xia Q and Wang HP: Reducing the oxidative stress mediates the cardioprotection of bicyclol against ischemia-reperfusion injury in rats. J Zhejiang Univ Sci B 14: 487-495, 2013.

25. Argaud L, Gateau-Roesch O, Raisky O, Loufouat J, Robert D and Ovize M: Postconditioning inhibits mitochondrial permeability transition. Circulation 111: 194-197, 2005.

26. Di Benedetto G, Scalzotto E, Mongillo $M$ and Pozzan T: Mitochondrial $\mathrm{Ca}^{2+}$ uptake induces cyclic AMP generation in the matrix and modulates organelle ATP levels. Cell Metab 17: 965-975, 2013.

27. Staat P, Rioufol G, Piot C, Cottin Y, Cung TT, L'Huillier I, Aupetit JF, Bonnefoy E, Finet G, André-Fouët X and Ovize M: Postconditioning the human heart. Circulation 112: 2143-2148, 2005 .
28. Maslov LN, Naryzhnaia NV, Hanuš L, Pei JM, Bă̌kov AN, Zhang I, Wang $\mathrm{H}$ and Khaliulin IG: Problem of end-effector of ischemic postconditioning of the heart. Ross Fiziol Zh Im I M Sechenova 99: 555-574, 2013 (In Russian).

29. Yang XM, Proctor JB, Cui L, Krieg T, Downey JM and Cohen MV: Multiple, brief coronary occlusions during early reperfusion protect rabbit hearts by targeting cell signaling pathways. J Am Coll Cardiol 44: 1103-1110, 2004

30. Bround MJ, Wambolt R, Luciani DS, Kulpa JE, Rodrigues B, Brownsey RW, Allard MF and Johnson JD: Cardiomyocyte ATP production, metabolic flexibility, and survival require calcium flux through cardiac ryanodine receptors in vivo. J Biol Chem 288: 18975-18986, 2013.

31. Darling CE, Jiang R, Maynard M, Whittaker P, Vinten-Johansen J and Przyklenk K: Postconditioning via stuttering reperfusion limits myocardial infarct size in rabbit hearts: Role of ERK1/2. Am J Physiol Heart Circ Physiol 289: H1618-H1626, 2005. 